REVIEW

\title{
Current evidence for recommendation of surgery, medical treatment and vitamin $D$ repletion in mild primary hyperparathyroidism
}

\author{
Jens Bollerslev ${ }^{1,2}$, Claudio Marcocci ${ }^{3}$, Manuel Sosa ${ }^{4}$, Jörgen Nordenström ${ }^{5}$, Roger Bouillon ${ }^{6}$ and Leif Mosekilde ${ }^{7}$ \\ ${ }^{1}$ Section of Specialized Endocrinology, Oslo University Hospital, Rikshospitalet and ${ }^{2}$ Faculty of Medicine, University of Oslo, N-O027 Oslo, Norway, \\ ${ }^{3}$ Department of Endocrinology and Metabolism, University of Pisa, Pisa, Italy, ${ }^{4}$ Bone Metabolic Unit, University of Las Palmas de Gran Canaria, Gran \\ Canaria, Spain, ${ }^{5}$ Department of Breast and Endocrine Surgery, Karolinska University Hospital, Stockholm, Sweden, ${ }^{6}$ Section of Experimental Medicine and \\ Endocrinology, University Hospital Leuven, Leuven, Belgium and ${ }^{7}$ Department of Endocrinology and Metabolism MEA, Aarhus University Hospital, \\ Aarhus C, Denmark \\ (Correspondence should be addressed to J Bollerslev at Section of Specialized Endocrinology, Oslo University Hospital, Rikshospitalet, University of Oslo; \\ Email: jens.bollerslev@medisin.uio.no)
}

\begin{abstract}
Management of patients with mild primary hyperparathyroidism (PHPT) has been widely discussed because most patients today do not have specific symptoms. While surgery is always an option, the recommendations for treatment have shifted, which mostly reflects changes in clinical practice. In this study, we aimed to evaluate evidence for the current recommendations concerning operation vs observation, repletion with vitamin D (VitD) and alternative medical management.

Surgery is followed by normalisation of calcium and parathyroid hormone (PTH) and a decrease in bone turnover followed by an increase in bone mass. It is not known what the consequences would be for the frequency of fractures. Randomised studies have indicated beneficial effects of operation on quality of life $(\mathrm{QoL})$, but the effects have been minor and inconsistent. Operation seems not to be superior to observation for cardiovascular risk factors. Although PHPT patients in average have slightly decreased plasma $250 \mathrm{H}$ VitD, severe symptomatic VitD deficiency seems not to be a characteristic of PHPT patients in Europe. However, if present, we recommend VitD substitution before final decision on surgical treatment. It is unknown whether routine VitD supplementation should be offered preoperatively to all patients with mild PHPT or as part of long-term medical treatment.

Targeted medical management could be an option for patients with contraindications to surgery. Antiresorptive therapy might be appropriate for patients with a low bone mass to prevent further bone loss. Calcimimetics could be tried to control serum calcium levels although there is no evidence of an effect on the hypercalcaemic symptoms or the QoL. Combined therapy with calcimimetics and alendronate could be considered for patients with hypercalcaemia and overt bone disease.
\end{abstract}

European Journal of Endocrinology 165 851-864

\section{Introduction}

In Europe, primary hyperparathyroidism (PHPT) has become a very common endocrine disorder. Usually with subtle or no disease-specific symptoms, it is often diagnosed by accident during the biochemical screening of primarily middle-aged or elderly patients (1). Thus, the term mild PHPT has been introduced and indications for the management of patients with the asymptomatic disease have been widely discussed over the last two decades, including at three international workshops aimed at giving general proposals for the handling of these patients in the clinic (2-4). As a result of these consensus conferences, recommendations to the managing clinicians have been modified in accordance with a gain in knowledge and evidence.
Before the era of multichannel biochemistry, PHPT was a multi-morbid condition with serious manifestations that included hyperparathyroid bone disease and frequent nephrolithiasis (5). The open access to calcium measurements changed the clinical presentation dramatically so that most patients nowadays present with minor or unspecific symptoms (6). In PHPT, the circulating parathyroid hormone (PTH) levels are inappropriately raised in relation to the levels of calcium, which is normally due to a monoclonal parathyroid adenoma $(85 \%)$ or multiglandular hyperplasia $(15 \%)$, while malignant parathyroid tumours are rare (7). The elevated PTH levels are related to a shift in the set point (Fig. 1), i.e. the normal sigmoid relationship between calcium and PTH still exists but at a higher level. This shift in the set point is typically 


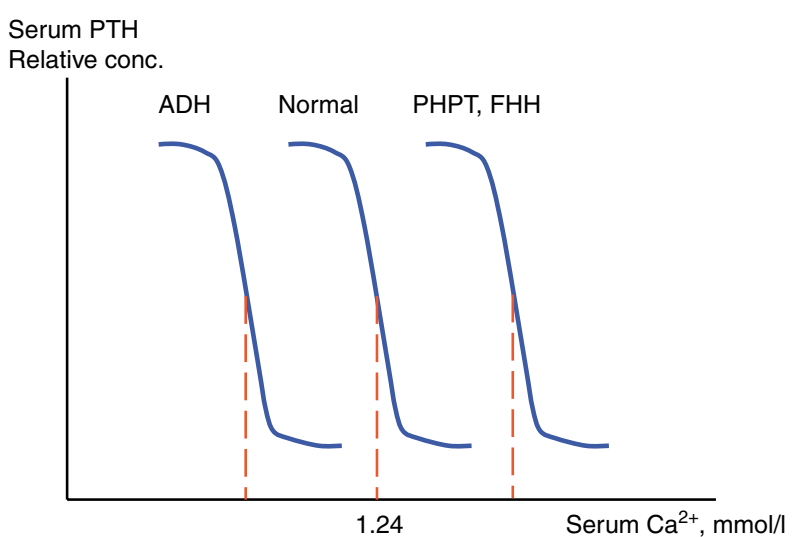

Figure 1 Sigmoid relationship between calcium in media (in cell cultures or in the circulation in vivo) and PTH secretion. The PTH set point is defined as a calcium concentration that corresponds to a $50 \%$ reduction in $\mathrm{PTH}$. The set point is increased in primary hyperparathyroidism (PHPT) and familial hypocalciuric hypercalcaemia $(\mathrm{FHH})$ and decreased in autosomal dominant hypocalcaemia $(A D H)$ due to a gain-of-function mutation in the calcium-sensing receptor. Adapted from J Bollerslev, L Rolighed and L Mosekilde Mild hyperparathyroisidm and metabolism of Vitamin D. IBMS BoneKEy 20118 342-351, with permission from the International Bone \& Mineral Society.

followed by a stable (equilibrium) hypercalcaemia over the years and is the basis for a potential nonintervention (8-12).

\section{Definition}

As no specific definition is provided, we suggest that mild hyperparathyroidism is a medical condition produced by an excess of PTH (familial hypocalciuric hypercalcaemia is excluded) producing stable hypercalcaemia. The main characteristics of mild hyperparathyroidism are that the patient is asymptomatic, has no hypercalcaemic symptoms, and there is no clinical evidence of bone, renal or stone disease.

\section{Aims}

In this article, we will critically evaluate the evidence for the current recommendations for management of mild PHPT concerning an operation vs observation without a surgical intervention, repletion with vitamin D (VitD) and alternative medical management.

\section{Epidemiology and morbidity}

Epidemiological and case-control studies have revealed increasing incidences of PHPT for unknown reasons; although among other causes, a low intake of VitD has been a focus (13-15). In the latest update from the Rochester Epidemiological Project through 2001, the incidence was estimated to be more than 21/100 000 persons/year, with a majority of the patients with a mild or asymptomatic disease (16). However, the incidence might be higher and the morbidity more pronounced in areas with a low VitD level $(13,14,17-20)$. The prevalence of PHPT is well described in middle-aged Scandinavian women. In two studies based on mammography screening, the prevalence was found to be $2.1 \%$ in postmenopausal, 55- to 77-year-old Swedish women (21) and remarkably even higher $(5.1 \%)$ in late premenopausal, 40- to 50-year-old females from the same area that were studied a decade later (22). Patients in these two studies were recruited from among presumably healthy women. It is of interest that a subsequent work up revealed that the women who received a diagnosis of PHPT had increased morbidity that was primarily from the cardiovascular and musculoskeletal system and included a lower bone mass $(22,23)$, compared with the controls from the same study population. Moreover, the identified patients had a lower quality of life (QoL) and more psychiatric symptoms. Epidemiological data in men are less well described, but the large MrOs study revealed a prevalence of PHPT of $0.7 \%$ (24).

\section{The safe threshold for calcium in mild PHPT}

Patients with PHPT are at risk for complications from the steadily increased PTH and calcium levels. Complications are related to insulin resistance (25) and therefore include the cardiovascular system (26-28), an increased risk of stones in the urinary tract (29), and a loss of bone mass and thereby a risk of fractures (30). Most data are based on case-control studies $(31,32)$ because only a few prospective studies have been performed $(11,12,33-36)$. In the recommendations for the management of patients with mild PHPT, a search for a safe calcium level has been crucial (2-4). However, so far, none of the long-term prospective studies have answered this question, and conclusive data are highly warranted. In the period between the first and the third international conference on the management of mild PHPT, the intervention level for calcium was reduced from 3.00 to $2.85 \mathrm{mmol} / \mathrm{l}(2,4)$, which primarily reflected a shift in clinical practice because background evidence was weak. In fact, in the Rochester Epidemiological Project of 435 patients with mild PHPT, the overall mortality was better compared with the background population (15). However, a higher maximal calcium level was an independent predictor of mortality with a relative risk $(\mathrm{RR})=1.3$ per $0.25 \mathrm{mmol} / \mathrm{l}$ (or per $\mathrm{mg} / \mathrm{dl}$ ) (confidence interval: $1.1-$ $1.6, P<0.02)(15)$. These data were in alignment with the Danish case-control studies based on a series of patients that were operated upon for PHPT (32). In the first series that spanned the period between 1979 and 1990 (mean age of 60 years, $72 \%$ female), the mean ionised calcium level was $1.65 \mathrm{mmol} / \mathrm{l}$ and the standard mortality rate (SMR) was 1.32 (1.09-1.67). However, patients that were operated on during the period 
between 1991 and 1997 (mean age of 61 years, 75\% female) had lower mean ionised calcium levels (1.54 mmol/l) and no significant increase in mortality (SMR: 1.22 (0.94-1.74)). The non-significant increase in SMR can of course be related to a type 2 error, but it is in accordance with the Rochester study (15). Importantly, indications for surgery in the latter study (32) were not given, and a serious selection bias cannot be ruled out. Thus, only long term, prospective and at the best randomised studies can solve the question of a safe calcium level in mild PHPT.

\section{Surgical treatment or medical observation?}

In general, surgical treatment of PHPT is recommended in cases of a symptomatic disease. Thus, patients with classical symptoms (hypercalcaemia, hyperparathyroid bone disease, low-energy fractures and renal stone disease) or patients with high calcium levels should be offered an operation (4). In modern Western clinics, the proportion of patients with clear indications for surgery is about $50 \%$ (6) and might even be decreasing with the enhanced awareness of the disease. The rest of the patient population, i.e. patients without organ-specific symptoms and patients with only mildly elevated calcium levels, are the focus for a discussion of treatment options, and it should be emphasised that the presence of subtle psychiatric symptoms or an impaired QoL should not be added to the list of criteria for surgery at this moment (37).

\section{Indications for surgery in mild PHPT}

As maintained by the third (2008) international workshop, surgery is always a valid option for the treatment of mild PHPT, but there was a consensus that surgery is especially recommended for a number of indications (4):

1. The total albumin-corrected calcium levels are more than $0.25 \mathrm{mmol} / \mathrm{l}$ above the upper limit of normal, which in our experience is $>2.80 \mathrm{mmol} / \mathrm{l}$ (corresponding to ionised calcium $>1.45 \mathrm{mmol} / \mathrm{l}$ ). We suggest using the mean value of three fasting measurements from the morning, and medications known to interfere with calcium levels are stopped for 4-6 weeks. It is also suggested that patients should be replete with VitD to unmask false low calcium levels (6), see below.

2. Significantly impaired kidney function is regarded as an absolute indication for surgery with a cut off level for the calculated creatinine clearance below $60 \mathrm{ml} / \mathrm{min}$.

3. A previous fragility fracture or a T-score for bone mineral density (BMD) lower than -2.5 in any compartment, including the forearm.

4. Less than 50 years of age.
Moreover, surgery is indicated in patients for whom medical surveillance is neither desired nor possible (4). In the period following the first NIH-initiated international workshop, the guidelines were changed for two very important aspects. The calcium intervention level has dropped from $3.00 \mathrm{mmol} / \mathrm{l}$, reflecting a shift in clinical practice more than published data (3). Osteoporosis, defined as a $T$-score less than -2.5 in any compartment, is now regarded as an indication for surgery, while originally a low Z-score in the forearm, which primarily represents cortical bone (the compartment most prone to bone loss in PHPT $(38,39)$ ), was solely regarded as an indication. This shift in the recommendation acknowledges a low BMD as a significant risk factor for fractures, also in PHPT. Accordingly, the presence of a previous fragility fracture, which is the most important risk factor for a new fracture, is now also regarded as an indication for surgery (4). The current guidelines are not entirely supported by evidence-based studies. Indeed, the summary statements of the 2008 workshop included two surgical criteria, namely bone and renal impairment, among the blueprints for further research.

\section{The success of and complications from surgery}

Proponents for the surgical treatment of mild PHPT stated that parathyroid surgery performed by an experienced surgeon is safe, cost-effective, and associated with a very high cure rate and a very low rate of perioperative morbidity (40). These statements were based on a recent large number of operations that showed no obvious differences in the success or complication rates between traditional neck explorations or modern, minimally invasive techniques. Primary parathyroidectomy (PTX) is usually reported to have a cure rate of $95-98 \%$ and a complication rate as low as $1-3 \%$, with a serious complication rate far below 1\% (41-43). The operative results reported from centres of excellence, however, may be difficult to obtain for routine clinical practice in non-specialised surgical departments. The Scandinavian Quality Register for parathyroid surgery (www.thyroid-parathyroidsurgery. com) is a large, multi-national register that collects data from 40 surgical departments in Sweden, Denmark and Norway. This register contains data (as of May 2011) on 5171 patients who underwent a PTX for PHPT during the period between 2005 and 2011. The median preoperative serum calcium concentration was $2.78 \mathrm{mmol} / \mathrm{l}$. The operative complication rate was $3 \%$ (1\% bleeding, $1 \%$ wound infection and $1 \%$ other serious complication). Follow-up data of patients with available 6 -month postoperative calcium values $(n=3629)$ disclosed the following: normocalcaemia, 85.2\%; hypercalcaemia, $7.2 \%$; calcium and/or VitD therapy for hypoparathyroidism, 6.3\%; calcium value below reference range (but apparently asymptomatic), $1.3 \%$. The Scandinavian Quality Register data clearly indicate 
that a significant proportion of patients in surgical departments may not have their hypercalcaemia corrected by a single operation, some may become hypocalcaemic and others will be prescribed calcium and/or VitD following the PTX.

\section{The cost-effectiveness of different treatment modalities}

Few studies on cost-effectiveness have been performed. Zanocco et al. (44) made a calculation based on a 60-year-old woman with mild PHPT who has three therapeutic options: i) surgical treatment, ii) observation without intervention and iii) treatment with calcimimetics. The life expectancy was estimated at 22 years. The cost effect per quality-adjusted life year (QUALY) was of the same magnitude for an operation as for observation (\$313 vs \$267 per QUALY). Thus, the authors found that monitoring was the least expensive but also the least effective option. This was, however, based on the assumption that the PTX normalised the QoL (perfect health), which so far has not been shown in prospective, controlled studies $(33,34,36)$, and on the success and complication rates that were published by expert centres. Compared with the conventional treatment, calcimimetics were not cost-effective. Recently, the same authors reviewed the literature and came to the same conclusion. Moreover, minimally invasive procedures with preoperative localisation appeared to be more cost-effective than the traditional neck exploration (45).

\section{Observation vs operation}

Most data in the literature are based on observational or case-control studies because only a few randomised, controlled studies on the treatment of mild PHPT have been performed $(33,34,36)$. Based on a long-term observational study $(11,12)$, it seems safe to observe patients with mild PHPT without intervention for several years, as long as the morbidity is closely monitored and the patients are offered surgery if indications appear during observation. The 15-year results of this non-randomised cohort were recently published (11), and this study seems to have had a high impact on the most recent consensus statement (1). The study showed that in the six patients that were followed for 15 years without surgery, a significant decrease in BMD was observed in the femoral neck and in the forearm after 12-13 years (11), as shown in Table 1.

Rao et al. (36) performed a randomised, controlled study of 53 patients with mild PHPT with the aim to evaluate the superiority of surgery compared with a conservative observation. Biochemistry, osteodensitometry, QoL (SF-36), and psychological function were measured at 6- or 12-month intervals for at least 24 months. Following an operation, calcium levels, PTH and the urinary excretion of calcium normalised,
Table 1 Level of evidence for statements in relation to surgical treatment vs observation in mild primary hyperparathyroidism. Levels of evidence according to Oxford Centre for Evidence-based Medicine Levels of Evidence. Evidence is categorised in five levels from 1 to 5 , where one is the highest level, with sub-levels $a$ and $b$ for levels 1, 2 and 3. http://www.cebm.net/index.aspx?o=1025.

\begin{tabular}{llc}
\hline Statement & Design & $\begin{array}{c}\text { Level of } \\
\text { evidence }\end{array}$ \\
\hline $\begin{array}{l}\text { Bone mass deteriorates during } \\
\text { long-term observation }\end{array}$ & $\begin{array}{c}1 \text { Cohort } \\
\text { study }\end{array}$ & 4 \\
$\begin{array}{l}\text { Treatment effect of surgery on bone } \\
\text { turnover }\end{array}$ & 2 RCT & $1 \mathrm{~b}$ \\
$\begin{array}{l}\text { Bone mass in the lumbar spine } \\
\text { increases by surgery }\end{array}$ & $2 \mathrm{RCT}$ & $1 \mathrm{~b}$ \\
$\begin{array}{l}\text { Bone mass in femoral neck increases } \\
\text { by surgery }\end{array}$ & $3 \mathrm{RCT}$ & $1 \mathrm{~b}$ \\
$\begin{array}{l}\text { Treatment effect of surgery on different } \\
\text { domains in generic QoL }\end{array}$ & $3 \mathrm{RCT}$ & $1 \mathrm{~b}$ \\
$\begin{array}{l}\text { questionnaires (inconsistent) } \\
\begin{array}{l}\text { psychiatric symptom score } \\
\text { No treatment effect of surgery on } \\
\text { cardiovascular risk factors }\end{array}\end{array}$ & $1 \mathrm{RCT}$ & $1 \mathrm{~b}$ \\
$\begin{array}{l}\text { No treatment effect of surgery on } \\
\text { echocardiography }\end{array}$ & $2 \mathrm{RCT}$ & $1 \mathrm{~b}$ \\
\hline
\end{tabular}

$\mathrm{RCT}$, randomised controlled trial.

whereas these variables were stable in the observed patients. In general, BMD increased following surgery, but the only significant treatment effect of surgery was found in the hip region, as shown in Table 1. With regard to QoL, a modest benefit of surgery was evident in the social and emotional role function $(P=0.007$ and 0.012 , respectively), whereas psychological function showed a minor decrease (anxiety and phobia) in favour of operation. The authors concluded that the minor benefits of surgery on BMD in the hip region, QoL and psychological functioning could be demonstrated in this 2-year study. But the small benefits of surgical intervention should be weighted against the risk of operation in these otherwise healthy individuals (36).

During 2002-2005, 412 consecutive patients with PHPT were referred to the Department of Endocrinology, University Hospital of Pisa, Italy. About half of the patients met the consensus criteria for surgery and the half who did not were potentially eligible for a randomised, 12-month study on operation vs observation for mild PHPT. Of the 214 potentially eligible patients, 53 patients were invited and 50 were included in the study (33). More than half of the patients (29) had clinically defined osteoporosis at inclusion. Biochemistry was normalised in all but one patient by surgery and was stable in the observation group for the entire 12 months of the study (33). A significant effect of surgical treatment on the percentage change in BMD was demonstrated for the lumbar spine and femoral neck (Table 1) but not for the distal third of radius. Bone markers decreased significantly following surgery and remained stable with observation (Table 1). Echocardiography did not show any changes in either 
group (Table 1). The different variables were not correlated with calcium or PTH either at baseline or during the study (33). Also, in this study, the generic SF-36 QoL questionnaire showed a modest but significant beneficial effect of surgery in the domains of bodily pain, general health, vitality and mental heath, as shown in Table 1 (33). The authors concluded the following: i) a successful PTX was followed by improvements in BMD and some variables of QoL and ii) most patients who were followed up without surgery did not show any sign of progression. Thus, PTX may be beneficial even in asymptomatic patients who do not meet any criteria for surgery. However, a rigorous risk/benefit assessment of PTX remains to be established (33).

The Scandinavian study on PHPT (SIPH) was based on the 1990 NIH criteria for the diagnosis and management of PHPT (2); however, with albumincorrected calcium levels in the range of 2.60$2.85 \mathrm{mmol} / \mathrm{l}$, they by chance almost met the most recent international recommendations (4). A total of 191 patients with mild PHPT were included and randomised to PTX or observation without intervention during 1999-2005. So far, data generated during the first 2 years of the study have been published $(34,35$, 46). In the first publication, data were reported based on those who had completed the year $1(n=119)$ and year 2 visits $(n=99)$ by the end of the inclusion period (34). As in the other randomised studies on PHPT $(33,36)$, the population consisted primarily of women (165 vs 26 men) with a mean age at inclusion of 64.2 years \pm 7.4 (S.D.). The bone mass at inclusion was normal based on normative Z-scores, whereas the population had a lower QoL (SF-36) and more psychopathological symptoms (comprehensive psychopathological rating scale (CPRS)) compared with normal Swedish controls (34). In the observation group, calcium, PTH and creatinine levels were stable in the 2-year period, whereas calcium and PTH normalised in the surgery group, as shown in Table 1. Consequently, bone mass was unchanged by observation and increased by surgery that resulted in a significant treatment effect of surgery on the lumbar spine $(P=0.047)$ and the femoral neck $(P=0.071$; Table 1$)$, which became significant in the subsequent study based on 116 observations in the second year $(P=0.016)$ (35). With regard to QoL and CPRS, only minor and inconsistent findings were observed (Table 1); however, they were in favour of surgery for the domains of RoleEmotional and Physical Functioning when the differences over 2 years were compared (34).

The following study on cardiovascular risk factors (CV) was based on 116 patients who had completed the 2-year follow-up by May 1st, 2008 (35). The study showed that the significant changes in bone mass in the 2-year perspective were due to a decrease in bone turnover, as biochemical markers were stable in the observation group and decreased markedly in the surgery group (35). Blood pressure, kidney function and indices of the metabolic syndrome, including detailed cholesterol parameters, demonstrated no effects in favour of surgery. A variety of CV-risk measures gave no indications of a beneficial effect of surgery (Table 1). Moreover, no deleterious effects of conservative management were demonstrated (35). Sahlgrenska University Hospital, Gothenburg performed systematic echocardiography in their patients who participated in the SIPH study and 2-year data from a sub-study in this centre have recently been published (46). The 49 patients who participated in the study did not differ from the SIPH cohort by any means. At baseline, PTH levels correlated significantly to the left ventricular mass index $(r=0.45$, $P=0.004)$ demonstrating the positive trophic effect of PTH on the heart. During the observation period, comprehensive echocardiography disclosed a borderline treatment effect of an operation (Table 1) on the left ventricular mass index $(P=0.066)$. Moreover, the diastolic dimension of the interventricular septum was significantly reduced $(P<0.001)$ in the surgery group, whereas no alterations were found during observation without intervention (46).

\section{Summary of randomised studies}

Based on published data from randomised studies (33-36, 46), it can be concluded that it seems safe to follow patients with mild PHPT for some (at least 2) years (Table 1). Detailed biochemical analysis of markers of PTH-target tissues has not given indications for beneficial effects of PTX compared with observation without intervention. However, PTX is, as expected, followed by a decrease in bone turnover with an increase in bone mass, although it is not in the most critical compartment, the cortical bone, based on the proximal forearm. Only a prolonged observation without surgery can reveal whether a new steady state in bone mass will be achieved, or if the observed change in bone mass after up to 2 years might be aggravated by a longer follow-up, as is indicated by a recent long-term observational study (11). Long-term studies are needed to evaluate the effect of surgical intervention on bone mineralisation because such changes might influence the fracture pattern and thereby recommendations for treatment. The three studies have all shown minor, yet inconsistent, favourable effects of operative treatment on different domains in the generic QoL questionnaire, SF-36 $(33,34,36)$, and the third international workshop on the management of asymptomatic PHPT questioned whether these changes were of clinical importance and did not recommend QoL as an indication for active treatment (1). Detailed echocardiography has been performed in two of the randomised studies (33) but only in a minor part of the SIPH study (46). So far, the studies did not reveal any significant treatment effects on variables of echocardiography $(33,46)$.

Thus, there have been no new evidence-based data since the last consensus conference modified the criteria 
for surgical interventions in patients with mild PHPT. However, it is useful to remember that most of these criteria were based on an overall consensus rather than evidence-based material. In view of the beneficial effects of a PTX on bone turnover and bone mass and the expected benefits on fracture risks, it can be questioned whether the age limit of 50 years should be increased for patients with low bone mass, as it is unlikely that the medical alternative (bisphosphonates) should be given for decades. Also, the consensus criterion of surgery for patients with a creatinine clearance below $60 \mathrm{ml} / \mathrm{min}$ implies that the very elderly patients could become surgical candidates purely on the basis of an age-related decrease in kidney function. This criterion should thus be carefully evaluated in the overall risk-benefit evaluation for very elderly patients.

\section{Substitution with VitD in PHPT}

\section{VitD insufficiency in PHPT: prevalence and aetiology}

Several studies have assessed the occurrence of VitD insufficiency and deficiency in PHPT and disclosed large variations worldwide in prevalence, severity and symptoms $(20,47)$. Most PHPT patients in Europe have only a moderate decrease in levels of plasma $250 H D$, as described later, and we rarely see patients with severe and symptomatic VitD deficiency that needs to be corrected. In contrast to Western clinics, severe symptomatic cases of PHPT with a marked VitD deficiency and a 15- to 20-fold increase in PTH levels are still seen in the developing countries such as India and China $(6,20)$. These differences in presentation are most likely explained by a diagnostic delay in the developing countries, although differences in nutrition status, food fortification, latitude, skin pigmentation and socioeconomic factors may also contribute (47-49). In one US cross-sectional study, patients with the lowest tertile of plasma $250 \mathrm{HD}(<40 \mathrm{nmol} / \mathrm{l})$ had significantly higher plasma levels of PTH and alkaline phosphatase and lower plasma phosphate levels than the remaining patients whose plasma calcium levels did not differ (13). This is in accordance with most other studies (47). Furthermore, a histomorphometric study of 30 patients with mild PHPT revealed that low levels of 250HD were associated with higher concentrations of PTH, greater catabolic effects in the cortical bone and greater anabolic effects in the trabecular bone (50).

Two European groups have recently reported plasma 250HD levels in PHPT (51-54). In the French study (51), plasma 250HD levels were available for 72 out of 145 consecutive PHPT patients. The frequency of VitD insufficiency, defined as plasma 250HD levels $<50 \mathrm{nmol} / \mathrm{l}$, was $93 \%$ and the plasma $250 \mathrm{HD}$ correlated inversely to the adenoma weight, plasma PTH levels and total plasma calcium. In a Danish cross-sectional study (52) including 289 consecutive Caucasian patients with PHPT and 289 sex-, age- and season-matched controls, patients with PHPT had significantly lower plasma $250 \mathrm{HD}$ levels compared with controls, which was independent of the season (52). An overall VitD insufficiency (plasma 250HD $<50 \mathrm{nmol} / \mathrm{l}$ ) was observed in $81 \%$ of the PHPT patients compared with $60 \%$ of the sex-, age- and seasonmatched controls $(P<0.001)$. During the summer, 77 vs $53 \%(P<0.001)$, respectively, had a VitD insufficiency compared with 86 vs $66 \%(P<0.001)$ during winter. A VitD deficiency $(25 \mathrm{OHD}<25 \mathrm{nmol} / \mathrm{l})$ was found in a third of the PHPT population compared with a fifth of the control population $(P<0.001)$. Both groups experienced seasonal variations in VitD levels that correlated with sun exposure (Fig. 2). However, the $250 H D$ levels were lower in patients throughout the year. In the patient population, a low plasma 250HD level was associated with higher levels of calcium, PTH and a biochemical marker of bone turnover and a lower bone mass in the femoral neck, and in the forearm. The inverse correlation between $250 \mathrm{HD}$ and PTH was hyperbolic, as it was in normal individuals (Fig. 3). The plasma 250HD level was not associated with adenoma weight, but the plasma PTH/adenoma weight ratio correlated inversely to $250 \mathrm{HD}(P<0.05)$ (53). There was a non-significant trend $(P=0.08)$ towards an increased risk of osteoporotic fractures with a low plasma 25OHD (52). In another study including 246

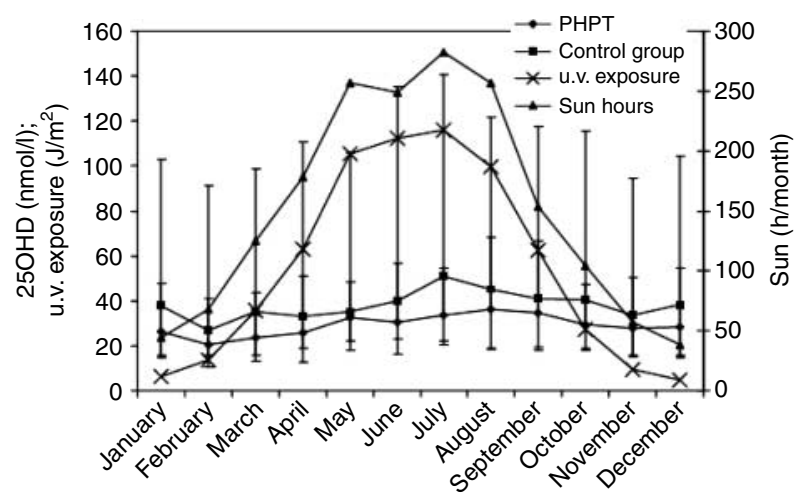

Figure 2 Seasonal variation in plasma 25OHD in 266 patients with primary hyperparathyroidism (PHPT) and 266 sex-, age- and season-matched normocalcaemic controls from general practice plotted against seasonal variations in sun hours/day and in regional u.v. irradiation. Vertical lines indicate s.D.'s calculated on logarithmically transformed $250 \mathrm{OH}$ values for PHPT and controls respectively. Summer values were higher than winter values in both groups ( $P<0.005$ and $P<0.05$ respectively). In all calendar months average $\mathrm{P}-25 \mathrm{OHD}$ levels were lower in PHPT patients than in controls (significant for March and July). Adapted from Moosgaard B, Vestergaard P, Heickendorff L, Melsen F, Christiansen P \& Mosekilde L. Vitamin D status, seasonal variations, parathyroid adenoma weight and bone mineral density in primary hyperparathyroidism. Clinical Endocrinology 200563 506-513 with permission from Wiley-Blackwell. 


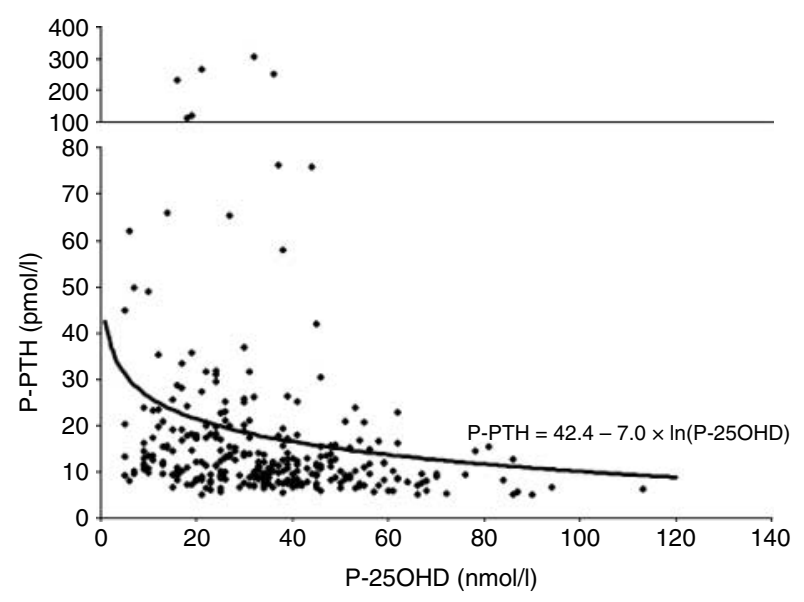

Figure 3 Inverse hyperbolic correlation between plasma 25OHD (P-25OHD) and P-PTH in 289 patients with PHPT. Note the discontinuation of the ordinate axis. Adapted from Moosgaard B, Vestergaard P, Heickendorff L, Melsen F, Christiansen P \& Mosekilde L. Vitamin D status, seasonal variations, parathyroid adenoma weight and bone mineral density in primary hyperparathyroidism. Clinical Endocrinology 200563 506-513 with permission from Wiley-Blackwell.

consecutive Caucasian PHPT patients, the BMD was reduced in the femoral neck $(P<0.001)$ and the forearm $(P<0.001)$, but normal in the lumbar spine $(P=0.11)$ (54). Plasma 250HD levels correlated inversely to alkaline phosphatase $(P<0.01)$ and positively to the BMD of the femoral neck $(P<0.005)$, the forearm $(P<0.05)$ and the whole body $(P<0.001)$ but not the spine (54).

Low VitD levels have also been related to cardiovascular function in mild PHPT. A recent US cross-sectional study showed that patients with biochemically mild PHPT had no evidence of an increased left ventricular mass, diastolic dysfunction or increased valvular calcifications as a group. However, an inverse relationship was observed between plasma 250HD levels and the left ventricular mass index, a well-known risk factor for cardiovascular disease and mortality (55). This relationship was not found in the SIPH sub-study, which is potentially due to a higher level of VitD in Scandinavia compared with the USA (46).

The reason for the reduced plasma 250HD levels in PHPT is not finally clarified. There is no evidence that the hepatic conversion of VitD to 250HD is regulated by PTH, VitD metabolites or other factors of calciumphosphate metabolism. The renal $1 \alpha$-hydroxylation is stimulated by PTH and hypophosphataemia. But due to the huge difference in the molar ratio between the two metabolites (1000-fold), it does not seem likely that the stimulated production of $1,25(\mathrm{OH})_{2} \mathrm{D}$ in PHPT should affect the circulating levels of the substrate (25OHD) substantially, even when taking into account the differences in the biological half-life (52). One likely possibility is that the elevated plasma $1,25(\mathrm{OH})_{2} \mathrm{D}$ increases the expression of the 24-hydroxylase gene in VitD-target tissues and thereby enhances the degradation of $25 \mathrm{OHD}$ and $1,25(\mathrm{OH})_{2} \mathrm{D}(56)$. This is supported by the spontaneous increase in serum $250 H D$ after successful parathyroid surgery (57). A contributing cause could be the increased body weight observed in PHPT patients (25) since obesity tends to be associated with lower plasma 250HD levels. However, a recent paper (58) has disclosed normal $250 H D$ levels in surgically cured previous hyperparathyroid patients in spite of continuing increased body weight.

A long-term VitD deficiency could potentially induce secondary hyperparathyroidism (SHPT), which could eventually become autonomous. This could occur either by stimulating the growth of the parathyroid gland tissue (hyperplasia) or by facilitating the development of parathyroid adenomas with parathyroid cells undergoing somatic mutations (59). This mechanism could explain the severity of PHPT in areas or populations with an endemic VitD deficiency $(18,19,60)$. However, the finding that $25 \mathrm{OHD}$ levels increase or normalise following a surgical cure for PHPT suggests that the 250HD insufficiency is not an innate characteristic in patients with mild PHPT in Europe (58), as shown in Table 2.

\section{The effects of VitD supplementation in PHPT}

The purpose of VitD treatment or supplementation in PHPT has been i) to improve the diagnostic separation between PHPT and SHPT; ii) to lower plasma PTH and bone turnover preoperatively to reduce the risk of postoperative hypocalcaemia caused by the hungry bone syndrome and iii) to evaluate the potential effects of VitD supplementation in the long-term medical

Table 2 Level of evidence for statements in relation to mild PHPT and vitamin D metabolism. Levels of evidence according to Oxford Centre for Evidence-based Medicine Levels of Evidence. Evidence is categorised in five levels from 1 to 5 , where one is the highest level, with sub-levels a and b for levels 1,2 and 3. http://www.cebm. net/index.aspx?o $=1025$.

\begin{tabular}{|c|c|c|}
\hline Statement & Design & $\begin{array}{l}\text { Level of } \\
\text { evidence }\end{array}$ \\
\hline $\begin{array}{l}\text { PHPT is associated with } \\
\text { vitamin D insufficiency/deficiency }\end{array}$ & $\begin{array}{l}\text { Clinical decision } \\
\text { rule }\end{array}$ & $2 b$ \\
\hline $\begin{array}{l}\text { Vitamin D supplementation increases } \\
\text { diagnostic separation between } \\
\text { PHPT and SHPT }\end{array}$ & Case series & 4 \\
\hline $\begin{array}{l}\text { Vitamin D treatment lowers } \\
\text { preoperative PTH levels }\end{array}$ & $\begin{array}{l}1 \text { Case series } \\
3 \text { Cohort studies }\end{array}$ & $\begin{array}{r}4 \\
2 b\end{array}$ \\
\hline $\begin{array}{l}\text { Vitamin D treatment lowers bone } \\
\text { turnover (inconsistent results) }\end{array}$ & $\begin{array}{l}3 \text { Low-quality } \\
\text { cohort studies }\end{array}$ & 4 \\
\hline $\begin{array}{l}\text { High vitamin D status decreases risk } \\
\text { of postoperative hypocalcaemia } \\
\text { and SHPT }\end{array}$ & 1 Case series & 4 \\
\hline
\end{tabular}


management of PHPT. This includes the effects on BMD, fracture risk, muscle function and cardiovascular risk. These goals should be met without an increased risk of hypercalcaemia, compromised renal function or renal stones.

Treatment with 1 $\alpha$-hydroxylated VitD metabolites has been used since the 1980s in selected patients with concomitant osteomalacia or osteitis fibrosa cystica to reduce preoperative plasma $\mathrm{PTH}$ and prevent postoperative hypocalcaemia (47). However, treatment with active VitD was later abandoned because of the risk of hypercalcaemia at higher doses and the lack of effect at lower doses that did not cause hypercalcaemia $(61,62)$.

\section{The diagnostic separation between PHPT and SHPT}

Only one study has addressed this question. In 2000, Kantorovich et al. (63) measured plasma levels of $250 H D$ and PTH in 229 patients referred for osteoporosis evaluation. Plasma 250HD was decreased $(<37 \mathrm{nmol} / \mathrm{l})$ and PTH increased $(>6.8 \mathrm{pmol} / \mathrm{l})$ in 15 of the patients. These patients were treated with $1250 \mu \mathrm{g}$ $\mathrm{D}_{2}$ twice-weekly for 10 weeks. Plasma PTH was normalised in ten of the patients who were considered to have SHPT. In the remaining five patients, plasma calcium was unchanged and plasma PTH remained elevated in spite of an increase in plasma 250HD (21$52 \mathrm{nmol} / \mathrm{l}$ ). Treatment with vitamin $\mathrm{D}_{2}$ increased BMD significantly in both the femoral neck and the lumbar spine. These patients were categorised as having PHPT. It was concluded that the diagnosis of PHPT can be obscured by a concomitant VitD insufficiency (63). However, two of the patients were normocalcaemic both before and after the VitD treatment and may be classified as having refractory SHPT. Furthermore, the PHPT diagnosis was only confirmed histopathologically following surgery in one of the remaining three hypercalcaemic patients. Due to the diagnostic uncertainty, this small study cannot justify the routine use of a short-term VitD supplementation as a diagnostic tool to distinguish PHPT from SHPT, as shown in Table 2. Larger studies based on histopathological findings and the effects of surgery as diagnostic gold standards are necessary.

\section{The preoperative lowering of plasma PTH}

There are no randomised, double-blind, controlled studies proving that treatment with VitD in PHPT reduces plasma PTH and bone turnover compared with a placebo. Evidence is based on case studies or uncontrolled/controlled historic cohort studies (Table 2). In an early study in 1985, LoCascio et al. (64) compared a daily oral treatment with $50 \mu \mathrm{g} \mathrm{D}$ for 1 month in six patients with severe PHPT and five healthy adults. In the PHPT patients, plasma 250HD and $1,25(\mathrm{OH})_{2} \mathrm{D}$ levels increased markedly, whereas
PTH decreased slightly with small increases in calcium and phosphate levels.

In 2005, Grey et al. (65) reported an uncontrolled cohort study of vitamin $\mathrm{D}_{3}$ treatment with $1250 \mu \mathrm{g}$ once-weekly for 1 month followed by $1250 \mu \mathrm{g}$ once monthly for 1 year in 21 patients with mild PHPT (total plasma calcium $<3 \mathrm{mmol} / \mathrm{l}$ ) and VitD insufficiency (plasma $250 \mathrm{HD}<50 \mathrm{nmol} / \mathrm{l}$ ). During treatment, the plasma $250 H D$ level increased from $28 \pm 13$ to $76 \pm$ $17 \mathrm{nmol} / \mathrm{l}$ after 6 months followed by stabilised values $(77 \pm 17 \mathrm{nmol} / \mathrm{l})$ for the next 6 months. There was a significant 24\% decrease in plasma PTH at 6 months $(P<0.007)$ and a $26 \%$ decrease at 12 months $(P<0.004)$. The mean levels of serum $1,25(\mathrm{OH})_{2} \mathrm{D}$, calcium, ionised calcium and phosphate did not change.

In a study on a larger scale, Grubbs et al. (66) reported a historic case series based on a clinical database. Out of 301 PHPT patients, 112 had moderate hypercalcaemia (average total plasma calcium $2.73 \pm 0.15 \mathrm{mmol} / \mathrm{l}$ ) and a plasma $250 \mathrm{HD}$ level $<75 \mathrm{nmol} / \mathrm{l}$. They were treated preoperatively with $1250 \mu \mathrm{g}$ of $\mathrm{D}_{2}$ daily for 2-210 days for a cumulative dose of $600-37500 \mu \mathrm{g}$. The plasma 250 HD level increased $156 \%$ from $45 \pm 20$ to $115 \pm$ $50 \mathrm{nmol} / \mathrm{l}(P<0.0001)$, whereas plasma PTH decreased $6.5 \%$ from $18.4 \pm 5.7$ to $17.2 \pm 5.7 \mathrm{nmol} / \mathrm{l}(P=0.014)$ and plasma calcium decreased $1.8 \%$ from $2.73 \pm 0.15$ to $2.68 \pm 0.15 \mathrm{mmol} / \mathrm{l}(P=0.008)$.

In 2009, Tucci (67) reported the effect of $\mathrm{D}_{2}$ treatment in a cohort study of 56 PHPT patients with moderate, asymptomatic hypercalcaemia (plasma calcium $2.74 \pm 0.10 \mathrm{mmol} / \mathrm{l}$ ) and low plasma 250HD levels $(28.7 \pm 8.0$, range of $17-60 \mathrm{nmol} / \mathrm{l})$. Fourteen patients were operated on successfully after VitD treatment. Initial doses of $1250 \mu \mathrm{g} \mathrm{D}$ once a week was evaluated after 8 weeks and adjusted individually from $20 \mu \mathrm{g}$ daily to $2500 \mu \mathrm{g}$ monthly to maintain plasma $25 \mathrm{OHD}$ levels $>75 \mathrm{nmol} / \mathrm{l}$. Plasma $25 \mathrm{OHD}$ levels increased significantly from $36 \pm 10$ at baseline to $89 \pm 33 \mathrm{nmol} / \mathrm{l}$ at 5 weeks and $95 \pm 22 \mathrm{nmol} / \mathrm{l}$ at 34 weeks $(P<0.0001)$. However, only an insignificant $8 \%$ decrease from 15.2 to $14.1 \mathrm{nmol} / \mathrm{l}$ was observed in the plasma PTH level from the baseline to week 10 (67).

In a recent cohort study in 2009, Isidro \& Ruano (68) reported the effects of a 1-year treatment with calcifediol $(25 \mathrm{OHD})$ at $8-16 \mu \mathrm{g} /$ day in 27 patients with asymptomatic PHPT (total plasma calcium $2.70 \pm 0.13 \mathrm{mmol} / \mathrm{l}$ ) and a concomitant VitD deficiency (plasma $250 \mathrm{HD}<50 \mathrm{nmol} / \mathrm{l}$, mean $28.7 \pm 8.0 \mathrm{nmol} / \mathrm{l}$ ). Twenty patients completed the 1-year treatment period. Plasma 250HD levels increased significantly after 3 months $(62.9 \pm 25 \mathrm{nmol} / \mathrm{l}, \quad P<0.01), 6$ months $(62.7 \pm 26.8 \mathrm{nmol} / \mathrm{l}, \quad P<0.01)$ and 12 months $(71.5 \pm 32.5 \mathrm{nmol} / \mathrm{l}, P<0.01)$. PTH levels decreased $30 \%$ during the first 6 months $(19.7 \pm 14.2$ vs $13.8 \pm 10.0 \mathrm{pmol} / \mathrm{l}, P=0.03)$. However, the decrease was no longer significant after 1 year of treatment $(19.7 \pm 14.2$ vs $17.2 \pm 14.6 \mathrm{pmol} / \mathrm{l}$, NS). Average 
plasma calcium levels remained unchanged at 3 months $(2.70 \pm 0.13 \mathrm{mmol} / \mathrm{l}), 6$ months $(2.73 \pm$ $0.10 \mathrm{mmol} / \mathrm{l})$ and 12 months $(73 \pm 0.10 \mathrm{mmol} / \mathrm{l})(68)$.

\section{A preoperative lowering of bone turnover}

The effects of VitD supplementation on bone turnover markers and BMD have not been evaluated in detail (Table 2). In the study by Grey et al. (65), plasma alkaline phosphatase levels decreased by $13 \%(P<0.02)$ at 6 months and $18 \%(P<0.02)$ at 12 months compared with baseline with an insignificant tendency $(P=0.13)$ towards a decrease in urine NTx excretion. There was no change in BMD in the lumbar spine or the femoral neck. In the study by Tucci (67), there was no change in the renal excretion of NTx. Furthermore, in the study by Isidro \& Ruano (68), plasma alkaline phosphatase levels did not change following the 1-year calcifediol treatment, in accordance with the nonsignificant alterations in PTH at that time point. Grubbs et al. (66) did not report bone markers and BMD.

\section{Postoperative hypocalcaemia and SHPT}

Postoperative hypocalcaemia may be caused by transient or permanent hypoparathyroidism following surgical intervention, unattended hypomagnesaemia, VitD insufficiency or hungry bone syndrome. The last two conditions may trigger an SHPT (69). Prior studies have identified a number of risk factors including bilateral neck exploration, a prior neck operation, a concurrent thyroidectomy, adenoma weight, the preoperative PTH level and preoperative bone turnover (69). No intervention study has appraised the effect of preoperative VitD treatment on postoperative hypocalcaemia (Table 2). However, based on a clinical database including 349 patients, Stewart et al. (69) reported the effect of a successful minimally invasive PTX of a single adenoma in 190 patients on the occurrence of postoperative hypocalcaemia and hyperparathyroidism. They found that $40 \%$ of patients had symptoms of hypocalcaemia (perioral and extremity numbness and paraesthesias) during the first ten postoperative days, but only six patients had biochemical hypocalcaemia (plasma calcium $<2.10 \mathrm{mmol} / \mathrm{l}$ ). Symptomatic patients had lower preoperative $250 \mathrm{HD}$ levels than asymptomatic patients $(51 \pm 40$ vs $72 \pm 56 \mathrm{nmol} / \mathrm{l}, P<0.004)$ without differences in pre- or post-operative plasma calcium or PTH levels or in the adenoma weight. Furthermore, the development of a postoperative SHPT correlated with preoperative PTH levels $(P<0.01)$ and lower preoperative 250HD levels $(P=0.05)$. The relationship to bone turnover markers was not reported. They suggested empirical postoperative calcium supplementation to patients with a low preoperative 250HD. A later study confirmed that patients with a preoperative VitD deficiency $(25 \mathrm{OHD}<62.5 \mathrm{pmol} / \mathrm{l})$ had higher postoperative PTH levels (70).

\section{Safety}

In the study by Grey et al. (65), serum calcium levels did not exceed $3.00 \mathrm{mmol} / \mathrm{l}$ in any of the patients. In two patients, the $24 \mathrm{~h}$ urinary calcium excretion exceeded $10 \mathrm{mmol}$ at the study end. No patient developed symptomatic renal stones during the study. The effects of the treatment on renal function and an assessment of asymptomatic renal stones were not reported. In the study by Grubbs et al. (66), six patients (5\%) had a mean asymptomatic increase in plasma calcium of $0.16 \mathrm{mmol} / \mathrm{l}$ during treatment. Isidro \& Ruano (68) reported a slight increase compared with baseline $(5.7 \pm 2.9 \mathrm{~mol})$ in renal calcium excretion after 3 months $(6.9 \pm 3.8 \mathrm{mmol}, P<0.05)$ and 12 months $(7.9 \pm 4.9 \mathrm{mmol}, P<0.05)$ of calcifediol treatment. Tucci (67) could not substantiate any risk of vitamin $\mathrm{D}_{2}$ treatment in PHPT at doses up to $2500 \mu \mathrm{g} / \mathrm{month}$. Plasma creatinine levels and the occurrence of renal stones were not reported in these studies (65-68).

\section{The benefits and risks of VitD repletion in mild PHPT}

It appears that a preoperative treatment with $\mathrm{D}_{3}$ $(64,65)$ and calcifediol (68) decreases circulating plasma PTH levels in VitD insufficient patients with PHPT, whereas $\mathrm{D}_{2}$ appears to be less effective $(66,67)$. The effects on bone markers and BMD are not conclusive. Preoperative VitD insufficiency has been associated with an increased risk of postoperative hypocalcaemic symptoms and SHPT, but intervention studies on the effect of preoperative VitD treatment is lacking. The beneficial effects on muscle function, QoL, cardiac risk and postoperative hypocalcaemia have not been explored. The treatment may raise serum calcium levels slightly and increase renal calcium excretions in a few patients. The long-term effects on renal stones have not been ascertained.

\section{Alternative medical treatment}

The aim of treatment in patients with PHPT is to normalise serum calcium and PTH levels, leading to an improvement in any associated symptoms. PTX is the only curative treatment and, as discussed, is successful in experienced hands. Few treatment alternatives are available for patients who are ineligible for or unwilling to undergo surgery and those for whom PTX has failed. Current options include the off-label use of antiresorptive drugs (bisphosphonates and oestrogen) and the calcimimetic cinacalcet. All patients not undergoing PTX should be advised to maintain a normal calcium intake. VitD deficiency, which appears to be associated with a more severe disease, should be corrected.

\section{Antiresorptive therapy}

Bone turnover is increased in PHPT, even in patients with an asymptomatic disease. Thus, drugs with an 
antiresorptive activity should be expected to be beneficial for the bones by decreasing the activation frequency, refilling the remodelling space and increasing mineralisation. These effects would be expected to increase the BMD. Oestrogen therapy was found to increase the femoral neck and the lumbar spine BMD in postmenopausal women with PHPT without affecting ionised calcium and PTH levels (71). Oestrogen therapy for a limited length of time can be a reasonable option in early postmenopausal women with mild PHPT and low BMD, who have no contraindications for the use of oestrogens, Table 3.

Bisphosphonates have been largely evaluated in patients with mild PHPT. The greatest experience has been collected using alendronate. Three randomised clinical trials have been performed. Rossini et al. (72) randomised 26 elderly women to alendronate $(10 \mathrm{mg}$ on alternate days) or no treatment for 2 years. Alendronate was associated with a decrease in bone turnover and an increase in BMD over baseline in the lumbar spine, hip and total body $(8.6 \pm 3.0,4.8 \pm 3.9$ and $1.2 \pm 1.4 \%$ respectively). Conversely, a $1.5 \%$

Table 3 Level of evidence for statements in relation to alternative medical treatment of mild PHPT. Levels of evidence according to Oxford Centre for Evidence-based Medicine Levels of Evidence. Evidence is categorised in five levels from 1 to 5 , where one is the highest level, with sub-levels $a$ and $b$ for levels 1, 2 and 3. http:// www.cebm.net/index.aspx?o $=1025$.

\begin{tabular}{|c|c|c|}
\hline Statement & Design & $\begin{array}{l}\text { Level of } \\
\text { evidence }\end{array}$ \\
\hline $\begin{array}{l}\text { Oestrogens treatment increases } \\
\text { bone mineral density in } \\
\text { postmenopausal women with } \\
\text { mild PHPT }\end{array}$ & $1 \mathrm{RCT}$ & $1 b$ \\
\hline $\begin{array}{l}\text { Alendronate treatment } \\
\text { decreases bone turnover } \\
\text { markers in patients with } \\
\text { mild PHPT }\end{array}$ & $3 \mathrm{RCT}$ & $1 a$ \\
\hline $\begin{array}{l}\text { Alendronate treatment increases } \\
\text { lumbar spine and hip bone } \\
\text { mineral density in patients } \\
\text { with mild PHPT }\end{array}$ & $3 \mathrm{RCT}$ & $1 a$ \\
\hline $\begin{array}{l}\text { Alendronate treatment is } \\
\text { associated with transient } \\
\text { changes in serum calcium and } \\
\text { PTH in patients with mild PHPT }\end{array}$ & $2 \mathrm{RCT}$ & $1 a$ \\
\hline $\begin{array}{l}\text { Antiresorptive therapies } \\
\text { (oestrogen and alendronate) } \\
\text { and parathyroidectomy increase } \\
\text { bone mineral density at the } \\
\text { lumbar spine and hip to a } \\
\text { similar degree in patients } \\
\text { with mild PHPT }\end{array}$ & $\begin{array}{l}1 \text { Meta- } \\
\text { analysis }\end{array}$ & $1 a$ \\
\hline $\begin{array}{l}\text { Cinacalcet lower and often } \\
\text { normalise serum calcium } \\
\text { in patients with mild PHPT }\end{array}$ & $\begin{array}{l}1 \text { RCT } \\
1 \text { Case series }\end{array}$ & $\begin{array}{l}1 b \\
4\end{array}$ \\
\hline $\begin{array}{l}\text { Cinacalcet has no effect on lumbar } \\
\text { spine and hip bone mineral } \\
\text { density in patients with mild } \\
\text { PHPT }\end{array}$ & $\begin{array}{l}1 \mathrm{RCT} \\
1 \text { Case series }\end{array}$ & $\begin{array}{l}1 b \\
4\end{array}$ \\
\hline
\end{tabular}

$\mathrm{RCT}$, randomised controlled trial. decrease in the femoral neck BMD was found in untreated patients (Table 3). Chow et al. (73) evaluated the effect of $10 \mathrm{mg}$ alendronate compared with placebo for 1 year in 48 postmenopausal women. Changes in BMD were significantly greater in patients treated with alendronate $(+3.8 \pm 4.0$ vs $0.2 \pm 2.8 \%(P=0.016)$ in the lumbar spine and $+4.2 \pm 6.0$ vs $-0.2 \pm 3.3 \%$ $(P=0.011)$ in femoral neck). Serum calcium levels decreased slightly with alendronate but not with placebo. Bone turnover markers decreased in alendronate-treated patients, as shown in Table 3.

In a multicentre randomised trial, Khan et al. (74) compared $10 \mathrm{mg}$ alendronate daily vs placebo in 44 patients with a mild, asymptomatic PHPT. After 1 year, patients receiving placebo were also given alendronate. Alendronate therapy was associated with an increase in the lumbar spine and total hip BMD (5.3 and $3.7 \%$ at year 1 and 6.8 and $4.0 \%$ at year 2 respectively). BMD in the distal radius did not change. Similar changes in BMD were observed in the second year of the protocol in patients initially assigned to placebo. Treatment with alendronate was associated with a decrease $(\sim 50 \%)$ in bone turnover markers (Table 3). Ionised calcium, phosphorus and PTH did not change during the study.

In summary, antiresorptive therapy in patients with PHPT is associated with no changes in serum calcium and PTH, even though a transient decrease in serum calcium and an increase of PTH can observed in the first month of therapy. The markers of bone turnover progressively decline and BMD increases in the lumbar spine and hip but not in the distal radius. The effects on bone turnover markers and BMD are comparable to those observed after PTX (75), as shown in Table 3. There are no randomised studies with fractures as an endpoint.

\section{Calcimimetics}

Cinacalcet is an allosteric modulator of the calciumsensing receptor that acts to sensitise this receptor to the extracellular calcium (76), thus inhibiting the synthesis and secretion of PTH and the renal tubular calcium reabsorption. In a dose-ranging study in patients with PHPT, cinacalcet administration was followed by the normalisation of serum calcium after the second dose that persisted during the entire 2-week study (77), as shown in Table 3. Conversely, the inhibitory effect on PTH secretion was transient (maximum effect 2-4 h after dosing) and the values almost returned to the pre-dose values in the following hours. In a 52-week placebo-controlled study, twicedaily cinacalcet therapy normalised serum calcium levels in $73 \%$ of cases. Enrolled patients had serum calcium concentrations $<3.13 \mathrm{mmol} / \mathrm{l}(12.5 \mathrm{mg} / \mathrm{dl})$. The pre-dose PTH concentration was only slightly reduced $(-13 \%)$ compared with baseline (Fig. 4), while serum phosphate levels rose significantly compared with placebo. The fasting but not the $24 \mathrm{~h}$ 

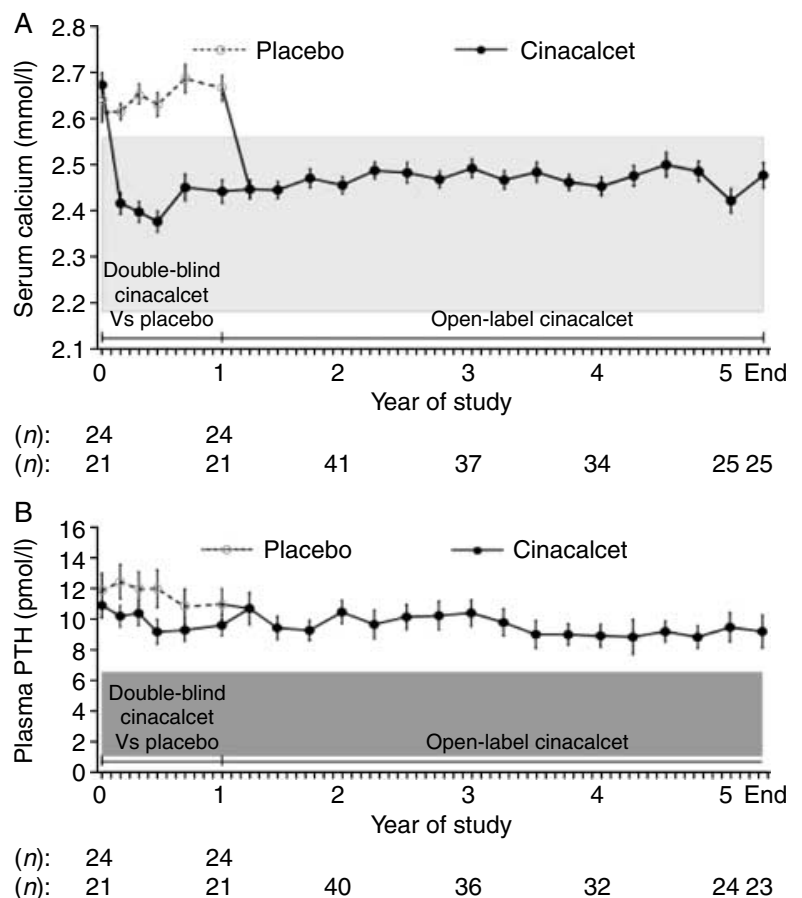

$\begin{array}{llllll}(n): & 21 & 21 & 40 & 36 & 32\end{array}$

Figure 4 Pre-dose (mean \pm S.E.M.) serum $\mathrm{Ca}$ and plasma intact PTH levels over time in the subjects included in the 4.5-year extension of the 52-week randomised, placebo-controlled trial. Fasting samples were taken before the morning dose of cinacalcet or placebo. The shaded areas represent the normal serum range. (A) Serum $\mathrm{Ca}$ levels. (B) Plasma intact PTH levels. The number of subjects $(n)$ followed during each year of the study is shown in each panel for the placebo (upper row of numbers) and cinacalcet-treated groups (lower row of numbers). Adapted from Peacock M, Bolognese MA, Borofsky M, Scumpia S, Sterling LR, Cheng S \& Shoback D.

Cinacalcet treatment of primary hyperparathyroidism: biochemical and bone densitometric outcomes in a five-year study. Journal of Clinical Endocrinology and Metabolism 200994 4860-4867 with permission from The Endocrine Society, USA.

urine calcium-creatinine ratio at 52 weeks in the cinacalcet group was significantly lower than in the placebo group. No significant changes in BMD were observed, as shown in Table 3. The adverse events were mild to moderate and mostly consisted of headaches and gastrointestinal complaints. Forty-five patients were followed for an additional 4 years (78). Serum calcium levels were maintained in the normal range in $\sim 80 \%$ of patients treated with cinacalcet. The BMD measurements did not change in the extension study. The adverse events were similar to those reported in the first year of the placebo-controlled trial, though two patients had kidney stones. There was no systematic information from the randomised studies on the effects of cinacalcet on hypercalcaemic symptoms or the QoL.

Cinacalcet could also be transiently used in a therapeutic trial to determine the benefits of lowering serum calcium levels in patients who meet the criteria for surgery but have significant comorbidities and a definite risk from surgery.
Cinacalcet has been effectively used to lower serum calcium levels in patients with MEN1-associated PHPT, a condition in which the rate of a successful surgery is lower than in the sporadic forms of $\operatorname{PHPT}(79,80)$.

Cinacalcet had been approved by the European Medicines Agency (EMA) in 2008 for: 'the reduction of hypercalcaemia in patients with PHPT, for whom PTX would be indicated on the basis of serum calcium levels (as defined by relevant treatment guidelines), but in whom PTX is not clinically appropriate or is contraindicated' (www.ema.europa.eu). Recently, the FDA has approved the use of cinacalcet for the treatment of severe hypercalcaemia in patients with PHPT who are unable to undergo a PTX (www.fda.gov).

\section{Targeted medical therapy}

In summary, no single or combined medical treatment can achieve a complete cure of PHPT, and, therefore, medical therapy should not be recommended as an alternative to PTX for patients who meet the surgical criteria.

\section{Conclusions}

Mild PHPT is a very common disease in the modern clinic and can safely be observed for at least several (1-2) years. Long-term data from randomised controlled studies will reveal whether this holds for a longer duration. Surgical intervention is always an option, especially if indications appear during observation. Based on randomised studies so far, the beneficial effects of surgery have been as expected, i.e. surgery is followed by the normalisation of calcium and PTH levels and a decrease in bone turnover and an increase in BMD in the lumbar spine and the femoral neck. There are no data so far on a beneficial effect of PTX in mild PHPT on fractures from controlled studies. The randomised studies have indicated beneficial effects of surgery on QoL based on the generic SF-36 questionnaire; however, the effects have been minor and inconsistent, and the potential placebo effect of the surgery can never be ruled out. Surgery does not seem to be superior to observation for cardiovascular risk factors, including variables of echocardiography in the shorter timeframe (1-2 years).

Although PHPT patients have slightly decreased plasma 250HD levels compared with controls, severe symptomatic VitD deficiency does not seem to be a characteristic of patients with mild PHPT in Europe. If present, however, we recommend substitution with VitD before a final decision on treatment is made. So far, the data does not support VitD substitution as a diagnostic tool in discriminating between PHPT and SHPT. The evidence for an effect of treatment with VitD in mild PHPT on a reduction in PTH levels and bone turnover is based on a case studies or uncontrolled/controlled historic cohort studies because randomised, placebo- 
controlled studies have not been published so far. Moreover, the effect of preoperative VitD treatment on postoperative hypocalcaemia has not been evaluated by an intervention study. We conclude that at present it is unknown whether routine VitD supplementation should be offered preoperatively to VitD insufficient patients with PHPT or as part of long-term medical treatment in all patients with mild PHPT. Large-scale randomised controlled studies are warranted to assess potential beneficial effects and side effects. However, severe symptomatic VitD deficiency should be corrected.

Targeted medical management could be an option in patients with contraindications to surgery or in those who are unwilling to undergo PTX. Antiresorptive therapy, particularly alendronate, may be appropriate for patients with low bone mass and mild hypercalcaemia to prevent further bone loss and decrease the risk of fracture. Conversely, cinacalcet could be used to control serum calcium levels in patients without an overt bone disease. However, the effect on hypercalcaemic symptoms, such as neuropsychological and cognitive abnormalities, and on QoL should be evaluated in randomised trials. Finally, a combined therapy with cinacalcet and alendronate could be considered in patients with hypercalcaemia and overt bone disease.

\section{Declaration of interest}

The authors declare that there is no conflict of interest that could be perceived as prejudicing the impartiality of the research reported.

\section{Funding}

This research did not receive any specific grant from any funding agency in the public, commercial or not-for-profit sector.

\section{References}

1 Silverberg SJ, Lewiecki EM, Mosekilde L, Peacock M \& Rubin MR. Presentation of asymptomatic primary hyperparathyroidism: proceedings of the third international workshop. Journal of Clinical Endocrinology and Metabolism 200994 351-365. (doi:10.1210/jc. 2008-1760)

$2 \mathrm{NIH}$ conference. Diagnosis and management of asymptomatic primary hyperparathyroidism: consensus development conference statement. Annals of Internal Medicine 1991114 593-597.

3 Bilezikian JP, Potts JT Jr, Fuleihan Gel-H, Kleerekoper M, Neer R, Peacock M, Rastad J, Silverberg SJ, Udelsman R \& Wells SA. Summary statement from a workshop on asymptomatic primary hyperparathyroidism: a perspective for the 21st century. Journal of Clinical Endocrinology and Metabolism 200287 5353-5361. (doi:10.1210/jc.2002-021370)

4 Bilezikian JP, Khan AA \& Potts JT Jr. Guidelines for the management of asymptomatic primary hyperparathyroidism: summary statement from the third international workshop. Journal of Clinical Endocrinology and Metabolism 200994 335-339. (doi:10.1210/jc. 2008-1763)

5 Cope 0 . The study of hyperparathyroidism at the Massachusetts General Hospital. New England Journal of Medicine 1966274 1174-1182. (doi:10.1056/NEJM196605262742105)
6 Silverberg SJ \& Bilezikian JP. The diagnosis and management of asymptomatic primary hyperparathyroidism. Nature Clinical Practice. Endocrinology \& Metabolism 20062 494-503. (doi:10. 1038/ncpendmet0265)

7 Fraser WD. Hyperparathyroidism. Lancet $20093 \mathbf{3 7 4}$ 145-158. (doi:10.1016/S0140-6736(09)60507-9)

8 Ayturk S, Gursoy A, Bascil TN, Ertugrul DT \& Guvener DN. Changes in insulin sensitivity and glucose and bone metabolism over time in patients with asymptomatic primary hyperparathyroidism. Journal of Clinical Endocrinology and Metabolism 200691 4260-4263. (doi:10.1210/jc.2005-2825)

9 Elvius M, Lagrelius A, Nygren A, Alveryd A, Christensson TA \& Nordenstrom J. Seventeen year follow-up study of bone mass in patients with mild asymptomatic hyperparathyroidism some of whom were operated on. European Journal of Surgery 1995161 863-869.

10 Rao DS, Wilson RJ, Kleerekoper M \& Parfitt AM. Lack of biochemical progression or continuation of accelerated bone loss in mild asymptomatic primary hyperparathyroidism: evidence for biphasic disease course. Journal of Clinical Endocrinology and Metabolism $1988 \quad 67$ 1294-1298. (doi:10.1210/jcem-67-61294)

11 Rubin MR, Bilezikian JP, McMahon DJ, Jacobs T, Shane E, Siris E, Udesky J \& Silverberg SJ. The natural history of primary hyperparathyroidism with or without parathyroid surgery after 15 years. Journal of Clinical Endocrinology and Metabolism 200893 3462-3470. (doi:10.1210/jc.2007-1215)

12 Silverberg SJ, Shane E, Jacobs TP, Siris E \& Bilezikian JP. A 10-year prospective study of primary hyperparathyroidism with or without parathyroid surgery. New England Journal of Medicine 1999341 1249-1255. (doi:10.1056/NEJM199910213411701)

13 Silverberg SJ, Shane E, Dempster DW \& Bilezikian JP. The effects of vitamin D insufficiency in patients with primary hyperparathyroidism. American Journal of Medicine 1999107 561-567. (doi:10. 1016/S0002-9343(99)00294-6)

14 Silverberg SJ. Vitamin D deficiency and primary hyperparathyroidism. Journal of Bone and Mineral Research 200722 (Suppl 2) V100-V104. (doi:10.1359/jbmr.07s202)

15 Wermers RA, Khosla S, Atkinson EJ, Grant CS, Hodgson SF, O'Fallon WM \& Melton LJ III. Survival after the diagnosis of hyperparathyroidism: a population-based study. American Journal of Medicine $1998 \mathbf{1 0 4}$ 115-122. (doi:10.1016/S00029343(97)00270-2)

16 Wermers RA, Khosla S, Atkinson EJ, Achenbach SJ, Oberg AL, Grant CS \& Melton LJ III. Incidence of primary hyperparathyroidism in Rochester, Minnesota, 1993-2001: an update on the changing epidemiology of the disease. Journal of Bone and Mineral Research 200621 171-177. (doi:10.1359/JBMR.050910)

17 Bilezikian JP, Meng X, Shi Y \& Silverberg SJ. Primary hyperparathyroidism in women: a tale of two cities - New York and Beijing. International Journal of Fertility and Women's Medicine $2000 \mathbf{4 5}$ $158-165$.

18 Harinarayan CV, Gupta N \& Kochupillai N. Vitamin D status in primary hyperparathyroidism in India. Clinical Endocrinology 199543 351-358. (doi:10.1111/j.1365-2265.1995.tb02043.x)

19 Rao DS, Honasoge M, Divine GW, Phillips ER, Lee MW, Ansari MR, Talpos GB \& Parfitt AM. Effect of vitamin D nutrition on parathyroid adenoma weight: pathogenetic and clinical implications. Journal of Clinical Endocrinology and Metabolism 200085 1054-1058. (doi:10.1210/jc.85.3.1054)

20 Rao DS, Agarwal G, Talpos GB, Phillips ER, Bandeira F, Mishra SK \& Mithal A. Role of vitamin D and calcium nutrition in disease expression and parathyroid tumor growth in primary hyperparathyroidism: a global perspective. Journal of Bone and Mineral Research 200217 (Suppl 2) N75-N80.

21 Lundgren E, Rastad J, Thrufjell E, Akerstrom G \& Ljunghall S. Population-based screening for primary hyperparathyroidism with serum calcium and parathyroid hormone values in menopausal women. Surgery 1997121 287-294. (doi:10. 1016/S0039-6060(97)90357-3) 
22 Siilin H, Rastad J, Ljunggren O \& Lundgren E. Disturbances of calcium homeostasis consistent with mild primary hyperparathyroidism in premenopausal women and associated morbidity. Journal of Clinical Endocrinology and Metabolism 200893 47-53. (doi:10.1210/jc.2007-0600)

23 Lundgren E, Szabo E, Ljunghall S, Bergstrom R, Holmberg L \& Rastad J. Population based case-control study of sick leave in postmenopausal women before diagnosis of hyperparathyroidism. BMJ $1998317848-851$.

24 Siilin H, Lundgren E, Mallmin H, Mellström D, Ohlsson C, Karlsson M, Orwoll E \& Ljunggren O. Prevalence of primary hyperparathyroidism and impact on bone mineral density in elderly men: MrOs Sweden. World Journal of Surgery 201135 1266-1272. (doi:10.1007/s00268-011-1062-2)

25 Bolland MJ, Grey AB, Gamble GD \& Reid IR. Association between primary hyperparathyroidism and increased body weight: a metaanalysis. Journal of Clinical Endocrinology and Metabolism 200590 1525-1530. (doi:10.1210/jc.2004-1891)

26 Fitzpatrick LA, Bilezikian JP \& Silverberg SJ. Parathyroid hormone and the cardiovascular system. Current Osteoporosis Reports 2008 6 77-83. (doi:10.1007/s11914-008-0014-8)

27 Hagstrom E, Lundgren E, Rastad J \& Hellman P. Metabolic abnormalities in patients with normocalcemic hyperparathyroidism detected at a population-based screening. European Journal of Endocrinology 2006155 33-39. (doi:10.1530/eje.1.02173)

28 Hagström E, Hellman P, Larsson TE, Ingelsson E, Berglund L, Sundström J, Melhus H, Held C, Lind L, Michaëlsson K \& Arnlöv J. Plasma parathyroid hormone and the risk of cardiovascular mortality in the community. Circulation $20091192765-2771$. (doi:10.1161/CIRCULATIONAHA.108.808733)

29 Mollerup CL, Vestergaard P, Frokjaer VG, Mosekilde L, Christiansen P \& Blichert-Toft M. Risk of renal stone events in primary hyperparathyroidism before and after parathyroid surgery: controlled retrospective follow up study. BMJ $2002 \mathbf{3 2 5}$ 807. (doi:10.1136/bmj.325.7368.807)

30 Vestergaard P \& Mosekilde L. Fractures in patients with primary hyperparathyroidism: nationwide follow-up study of 1201 patients. World Journal of Surgery 200327 343-349. (doi:10. 1007/s00268-002-6589-9)

31 Vestergaard P \& Mosekilde L. Cohort study on effects of parathyroid surgery on multiple outcomes in primary hyperparathyroidism. BMJ 2003327 530-534. (doi:10.1136/bmj.327. 7414.530)

32 Vestergaard P, Mollerup CL, Frokjaer VG, Christiansen P, BlichertToft M \& Mosekilde L. Cardiovascular events before and after surgery for primary hyperparathyroidism. World Journal of Surgery 200327 216-222. (doi:10.1007/s00268-002-6589-9)

33 Ambrogini E, Cetani F, Cianferotti L, Vignali E, Banti C, Viccica G, Oppo A, Miccoli P, Berti P, Bilezikian JP, Pinchera A \& Marcocci C. Surgery or surveillance for mild asymptomatic primary hyperparathyroidism: a prospective, randomized clinical trial. Journal of Clinical Endocrinology and Metabolism 200792 3114-3121. (doi:10.1210/jc.2007-0219)

34 Bollerslev J, Jansson S, Mollerup CL, Nordenström J, Lundgren E, Tørring O, Varhaug JE, Baranowski M, Aanderud S, Franco C, Freyschuss B, Isaksen GA, Ueland T \& Rosen T. Medical observation, compared with parathyroidectomy, for asymptomatic primary hyperparathyroidism: a prospective, randomized trial. Journal of Clinical Endocrinology and Metabolism 200792 1687-1692. (doi:10. 1210/jc.2006-1836)

35 Bollerslev J, Rosen T, Mollerup CL, Nordenström J, Baranowski M, Franco C, Pernow Y, Isaksen GA, Godang K, Ueland T \& Jansson Son behalf of the SIPH Study Group. Effect of surgery on cardiovascular risk factors in mild primary hyperparathyroidism. Journal of Clinical Endocrinology and Metabolism 200994 2255-2261. (doi:10.1210/ jc.2008-2742)

36 Rao DS, Phillips ER, Divine GW \& Talpos GB. Randomized controlled clinical trial of surgery versus no surgery in patients with mild asymptomatic primary hyperparathyroidism. Journal of Clinical Endocrinology and Metabolism 200489 5415-5422. (doi:10.1210/jc.2004-0028)
37 Walker MD \& Silverberg SJ. Parathyroidectomy in asymptomatic primary hyperparathyroidism: improves "bones" but not "psychic moans". Journal of Clinical Endocrinology and Metabolism 200792 1613-1615. (doi:10.1210/jc.2007-0551)

38 Christiansen P, Steiniche T, Vesterby A, Mosekilde L, Hessov I \& Melsen F. Primary hyperparathyroidism: iliac crest trabecular bone volume, structure, remodeling, and balance evaluated by histomorphometric methods. Bone 199213 41-49. (doi:10. 1016/8756-3282(92)90360-9)

39 Christiansen P, Steiniche T, Brixen K, Hessov I, Melsen F, Heickendorff L \& Mosekilde L. Primary hyperparathyroidism: effect of parathyroidectomy on regional bone mineral density in Danish patients: a three-year follow-up study. Bone 199925 589-595. (doi:10.1016/S8756-3282(99)00207-0)

40 Udelsman R, Pasieka JL, Sturgeon C, Young JE \& Clark OH. Surgery for asymptomatic primary hyperparathyroidism: proceedings of the third international workshop. Journal of Clinical Endocrinology and Metabolism 200994 366-372. (doi:10.1210/ jc.2008-1761)

41 Irvin GL III, Solorzano CC \& Carneiro DM. Quick intraoperative parathyroid hormone assay: surgical adjunct to allow limited parathyroidectomy, improve success rate, and predict outcome. World Journal of Surgery 200428 1287-1292. (doi:10.1007/ s00268-004-7708-6)

42 Udelsman R. Six hundred fifty-six consecutive explorations for primary hyperparathyroidism. Annals of Surgery 2002235 665-670. (doi:10.1097/00000658-200205000-00008)

43 Westerdahl J \& Bergenfelz A. Unilateral versus bilateral neck exploration for primary hyperparathyroidism: five-year follow-up of a randomized controlled trial. Annals of Surgery $2007 \mathbf{2 4 6}$ 976-980. (doi:10.1097/SLA.0b013e31815c3ffd)

44 Zanocco K, Angelos P \& Sturgeon C. Cost-effectiveness analysis of parathyroidectomy for asymptomatic primary hyperparathyroidism. Surgery 2006140 874-881. (doi:10.1016/j.surg.2006.07. 032)

45 Zanocco K, Heller M \& Sturgeon C. Cost-effectiveness of parathyroidectomy for primary hyperparathyroidism. Endocrine Practice 201117 (Suppl 1) 69-74. (doi:10.4158/EP10311.RA)

46 Persson A, Bollerslev J, Rosen T, Mollerup CL, Franco C, Isaksen GA, Ueland T, Jansson S \& Caidahl K \& SIPH Study Group. Effect of surgery on cardiac structure and function in mild primary hyperparathyroidism. Clinical Endocrinology $2011 \mathbf{7 4}$ 174-180. (doi:10.1111/j.1365-2265.2010.03909.x)

47 Rolighed L, Bollerslev J \& Mosekilde L. Vitamin D treatment in primary hyperparathyroidism. Current Drug Safety 20116 100-107.

48 Hagenau T, Vest R, Gissel TN, Poulsen CS, Erlandsen M, Mosekilde L \& Vestergaard P. Global vitamin D levels in relation to age, gender, skin pigmentation and latitude: an ecologic metaregression analysis. Osteoporosis International 200920 133-140. (doi:10.1007/s00198-008-0626-y)

49 Lips P. Vitamin D deficiency and secondary hyperparathyroidism in the elderly: consequences for bone loss and fractures and therapeutic implications. Endocrine Reviews 200122 477-501. (doi:10.1210/er.22.4.477)

50 Stein EM, Dempster DW, Udesky J, Zhou H, Bilezikian JP, Shane E \& Silverberg SJ. Vitamin D deficiency influences histomorphometric features of bone in primary hyperparathyroidism. Bone $2011 \mathbf{4 8}$ 557-561. (doi:10.1016/j.bone.2010.10.004)

51 Boudou P, Ibrahim F, Cormier C, Sarfati E \& Souberbielle JC. Potential utility of high preoperative levels of serum type I collagen markers in postmenopausal women with primary hyperparathyroidism with respect to their short-term variations after parathyroidectomy. Journal of Bone and Mineral Metabolism 2009 27 240-246. (doi:10.1007/s00774-008-0033-7)

52 Moosgaard B, Vestergaard P, Heickendorff L, Melsen F, Christiansen P \& Mosekilde L. Vitamin D status, seasonal variations, parathyroid adenoma weight and bone mineral density in primary hyperparathyroidism. Clinical Endocrinology 200563 506-513. (doi:10.1111/j.1365-2265.2005.02371.x) 
53 Moosgaard B, Vestergaard P, Heickendorff L, Melsen F, Christiansen P \& Mosekilde L. Plasma 25-hydroxyvitamin D and not 1,25-dihydroxyvitamin $\mathrm{D}$ is associated with parathyroid adenoma secretion in primary hyperparathyroidism: a cross-sectional study. European Journal of Endocrinology 2006 155 237-244. (doi:10.1530/eje.1.02197)

54 Moosgaard B, Christensen SE, Vestergaard P, Heickendorff L, Christiansen P \& Mosekilde L. Vitamin D metabolites and skeletal consequences in primary hyperparathyroidism. Clinical Endocrinology 200868 707-715. (doi:10.1111/j.1365-2265.2007. 03109.x)

55 Walker MD, Fleischer JB, Di Tullio MR, Homma S, Rundek T, Stein EM, Zhang C, Taggart T, McMahon DJ \& Silverberg SJ. Cardiac structure and diastolic function in mild primary hyperparathyroidism. Journal of Clinical Endocrinology and Metabolism 201095 2172-2179. (doi:10.1210/jc.2009-2072)

56 Zierold C, Mings JA \& DeLuca HF. Regulation of 25-hydroxyvitamin $\mathrm{D}_{3}$-24-hydroxylase mRNA by 1,25-dihydroxyvitamin $\mathrm{D}_{3}$ and parathyroid hormone. Journal of Cellular Biochemistry 2003 88 234-237. (doi:10.1002/jcb.10341)

57 Farahnak P, Larfars G, Sten-Linder M \& Nilsson IL. Mild primary hyperparathyroidism: vitamin D deficiency and cardiovascular risk markers. Journal of Clinical Endocrinology and Metabolism 2011 96 2112-2118. (doi:10.1210/jc.2011-0238)

58 Amstrup AK, Rejnmark L, Vestergaard P, Sikjaer T, Rolighed L, Heickendorff L \& Mosekilde L. Vitamin D status, physical performance and body mass in patients surgically cured for primary hyperparathyroidism compared with healthy controls - a cross-sectional study. Clinical Endocrinology $2011 \mathbf{7 4} 130-136$. (doi:10.1111/j.1365-2265.2010.03906.x)

59 Arnold A, Shattuck TM, Mallya SM, Krebs LJ, Costa J, Gallagher J, Wild Y \& Saucier K. Molecular pathogenesis of primary hyperparathyroidism. Journal of Bone and Mineral Research 2002 17 (Suppl 2) N30-N36.

60 Sultan AH, Bruckner FE \& Eastwood JB. Association between prolonged dietary vitamin D deficiency and autonomous hyperparathyroidism. BMJ 1989299 236-237. (doi:10.1136/ bmj.299.6693.236)

61 Heath DA, Van't HW, Barnes AD \& Gray JG. Value of 1-alphahydroxy vitamin $\mathrm{D}_{3}$ in treatment of primary hyperparathyroidism before parathyroidectomy. BMJ 19791 450-452. (doi:10.1136/ bmj.1.6161.450)

62 Lind L, Wengle B, Sorensen $\mathrm{OH}$, Wide L, Akerstrom G \& Ljunghall S. Treatment with active vitamin D (alphacalcidol) in patients with mild primary hyperparathyroidism. Acta Endocrinologica 1989120 250-256.

63 Kantorovich V, Gacad MA, Seeger LL \& Adams JS. Bone mineral density increases with vitamin $\mathrm{D}$ repletion in patients with coexistent vitamin D insufficiency and primary hyperparathyroidism. Journal of Clinical Endocrinology and Metabolism 200085 3541-3543. (doi:10.1210/jc.85.10.3541)

64 LoCascio V, Adami S, Galvanini G, Ferrari M, Cominacini L \& Tartarotti D. Substrate-product relation of 1-hydroxylase activity in primary hyperparathyroidism. New England Journal of Medicine 1985313 1123-1125. (doi:10.1056/NEJM198510313 131804)

65 Grey A, Lucas J, Horne A, Gamble G, Davidson JS \& Reid IR. Vitamin D repletion in patients with primary hyperparathyroidism and coexistent vitamin D insufficiency. Journal of Clinical Endocrinology and Metabolism 200590 2122-2126. (doi:10. 1210/jc.2004-1772)

66 Grubbs EG, Rafeeq S, Jimenez C, Feng L, Lee JE, Evans DB \& Perrier ND. Preoperative vitamin D replacement therapy in primary hyperparathyroidism: safe and beneficial? Surgery 2008 144 852-858. (doi:10.1016/j.surg.2008.06.032)

67 Tucci JR. Vitamin D therapy in patients with primary hyperparathyroidism and hypovitaminosis D. European Journal of Endocrinology 2009161 189-193. (doi:10.1530/EJE-08-0901)
68 Isidro ML \& Ruano B. Biochemical effects of calcifediol supplementation in mild, asymptomatic, hyperparathyroidism with concomitant vitamin D deficiency. Endocrine 200936 305-310. (doi:10.1007/s12020-009-9211-1)

69 Stewart ZA, Blackford A, Somervell H, Friedman K, Garrett-Mayer E, Dackiw AP \& Zeiger MA. 25-Hydroxyvitamin D deficiency is a risk factor for symptoms of postoperative hypocalcemia and secondary hyperparathyroidism after minimally invasive parathyroidectomy. Surgery 2005138 1018-1025. (doi:10.1016/j.surg.2005.09.018)

70 Untch BR, Barfield ME, Dar M, Dixit D, Leight GS Jr \& Olson JA Jr. Impact of 25-hydroxyvitamin $\mathrm{D}$ deficiency on perioperative parathyroid hormone kinetics and results in patients with primary hyperparathyroidism. Surgery $2007 \mathbf{1 4 2}$ 1022-1026. (doi:10. 1016/j.surg.2007.09.026)

71 Grey AB, Stapleton JP, Evans MC, Tatnell MA \& Reid IR. Effect of hormone replacement therapy on bone mineral density in postmenopausal women with mild primary hyperparathyroidism. A randomized, controlled trial. Annals of Internal Medicine 1996 $125360-368$

72 Rossini M, Gatti D, Isaia G, Sartori L, Braga V \& Adami S. Effects of oral alendronate in elderly patients with osteoporosis and mild primary hyperparathyroidism. Journal of Bone and Mineral Research 200116 113-119. (doi:10.1359/jbmr.2001.16.1.113)

73 Chow CC, Chan WB, Li JK, Chan NN, Chan MH, Ko GT, Lo KW \& Cockram CS. Oral alendronate increases bone mineral density in postmenopausal women with primary hyperparathyroidism. Journal of Clinical Endocrinology and Metabolism 200388 581-587. (doi:10.1210/jc.2002-020890)

74 Khan AA, Bilezikian JP, Kung AW, Ahmed MM, Dubois SJ, Ho AY, Schussheim D, Rubin MR, Shaikh AM, Silverberg SJ, Standish TI, Syed Z \& Syed ZA. Alendronate in primary hyperparathyroidism: a double-blind, randomized, placebo-controlled trial. Journal of Clinical Endocrinology and Metabolism 200489 3319-3325. (doi:10.1210/jc.2003-030908)

75 Sankaran S, Gamble G, Bolland M, Reid IR \& Grey A. Skeletal effects of interventions in mild primary hyperparathyroidism: a meta-analysis. Journal of Clinical Endocrinology and Metabolism 201095 1653-1662. (doi:10.1210/jc.2009-2384)

76 Nemeth EF, Heaton WH, Miller M, Fox J, Balandrin MF, Van Wagenen BC, Colloton M, Karbon W, Scherrer J, Shatzen E, Rishton G, Scully S, Qi M, Harris R, Lacey D \& Martin D. Pharmacodynamics of the type II calcimimetic compound cinacalcet HCl. Journal of Pharmacology and Experimental Therapeutics $2004 \mathbf{3 0 8}$ 627-635. (doi:10.1124/jpet.103.057273)

77 Shoback DM, Bilezikian JP, Turner SA, McCary LC, Guo MD \& Peacock M. The calcimimetic cinacalcet normalizes serum calcium in subjects with primary hyperparathyroidism. Journal of Clinical Endocrinology and Metabolism 200388 5644-5649. (doi:10.1210/jc.2002-021597)

78 Peacock M, Bolognese MA, Borofsky M, Scumpia S, Sterling LR, Cheng S \& Shoback D. Cinacalcet treatment of primary hyperparathyroidism: biochemical and bone densitometric outcomes in a five-year study. Journal of Clinical Endocrinology and Metabolism 200994 4860-4867. (doi:10.1210/jc.2009-1472)

79 Falchetti A, Cilotti A, Vaggelli L, Masi L, Amedei A, Cioppi F, Tonelli F \& Brandi ML. A patient with MEN1-associated hyperparathyroidism, responsive to cinacalcet. Nature Clinical Practice. Endocrinology \& Metabolism 20084 351-357.

80 Moyes VJ, Monson JP, Chew SL \& Akker SA. Clinical use of cinacalcet in MEN1 hyperparathyroidism. International Journal of Endocrinology 2010 2010 906163. (doi:10.1155/2010/906163)

Received 30 June 2011

Revised version received 7 September 2011

Accepted 28 September 2011 